\title{
Um precursor desconhecido: a NSFNET e as redes pregressas a Internet
}

\author{
João Martins 1 \\ Iuperj \\ joaomartins@iuperj.br
}

\begin{abstract}
Resumo: Analise de parte do desenvolvimento da Internet - a criação da NSFNET entre 1979-1985 - que se justifica pela necessidade de sanar equívocos nas narrativas sobre a criação da rede; o principal deles, a suposição da Arpanet como único empreendimento antes da Web comercial. Observa-se um projeto pregresso central, porém esquecido, demonstrando que a Net relaciona-se não com o temor de holocausto nuclear, mas sim às tarefas de manutenção da hegemonia estadunidense no cenário de desenvolvimento tecnológico global. O problema envolve uma análise politico-econômica das ações de Estado: observa-se certo embate entre agências da burocracia governamental para se demonstrar sua importância na constituição técnico-econômica do meio de comunicação que surge.
\end{abstract}

Palavras-Chave: Computador como meio de comunicação, análise institucional do Estado; políticas de ciência e tecnologia.

\begin{abstract}
Analyze of part of the development of the Internet - the creation of NSFNET between 1979-1985 - which justify itself by the necessity to correct some misunderstandings about the creation of the Net; the most important is the supposition that Arpanet was the only investment before commercial use of Web. It observes an important and forgotten project, demonstrating that the Net relates not with the fear of a nuclear holocaust, but with the tasks of maintenance of EUA's hegemony in the international technology development. The task involves a political-economical analysis of the actions of state in R\&D. A dispute between governmental agencies will be analyzed, trying to demonstrate his importance for the development of a technical and economical structure of the medium that was, at that time, being constructed.
\end{abstract}

Key words: computer as a communication device; institutional analysis of state; scientific and technological policies.

\footnotetext{
${ }^{1}$ Mestre em Comunicação (UFF), doutorando em sociologia (Iuperj).
} 
Résume: Analyse de part du développement de Internet - la création du NSFNET entre 1979-1985 - qui on justifie par la besoin du corriger équivoques dans le récit sur la création du Réseau; le principal est la supposition du Arpanet comme unique entreprise avant le Web commercial. On enquête un projet antérieur primordial, néanmoins négligent, démontrai que la Net on identifie non avec le peur du holocauste nucléaire, mais avec les travails du maintenance du hégémonie estadunidense dans le contexte du développement technologique globale. Le problème enveloppe une analyse politique-économique du actes du état; on enquête certain compétition entre agences de bureaucratie de gouverne pour démontrer sa importance dans la constitution technique et économique du moins de communication que apparaître.

Mot-clés: ordinateur comme moins du communication; analyse institutionnel du état; politiques de science et technologie.

Resume: investigación de parte do desenvolvimiento da Internet - la creación da NSFNET entre 1979-1985 - que se justifica pela necesidad de sanar equívocos en las narrativas sobre la creación da red; lo principal es la suposición da Arpanet como única empresa antes da Web comercial. Observa-se un projeto anterior central, sin embargo olvidado, demostrando que a Net relaciona-se non com el temor de holocausto nuclear, mas si a las tareas de manutención da hegemonía estadunidense no escenario de desenvolvimiento tecnológico global. O problema envolve una análisis político-económica das acciones de Estado: observa-se cierto embate entre agencias da burocracia gubernamental para se demonstrar su importancia na construcción técnico-económica do medio de comunicación que surge.

Palabras-Clave: Computador como medio de comunicación, análisis institucional do Estado; políticas de ciencia e tecnología.

\section{Introdução}

Dois traços são notáveis na discussão sobre as "novas tecnologias" digitais de comunicação. Por um lado, impressiona o esforço exclusivamente dedicado à análise da assim chamada "cibercutura", aquelas manifestações sociais criadas pela popularização de certos instrumentos tecnológicos. O impacto de tal idéia fora imenso. O tópico, na verdade, parece ter monopolizado praticamente todas as atenções que se debruçaram sobre o tema. É digno de nota o imenso material dedicado a entendê-lo em seus vários desdobramentos, seja em termos da reformulação cultural que tem como marca o declínio do individualismo e a “retribalização" (Lemos 2002); seja da perspectiva da transição da racionalidade letrada para o "universal sem totalidade" da "cibercultura" (Levy 1990, 1997); seja da 
perspectiva da transformação biológica dos indivíduos como parte do processo de transição ao provável "pós-humano" (Sibilia 2002); seja do ponto de vista da rearrumação social macro, na qual a organização coletiva tende a se configurar em prol de um arranjo contemporâneo em "redes" (Castells 1996).

Os problemas político-econômicos contidos nas "redes", por outro lado, encontraram muito pouca repercussão. O projeto social do qual as tecnologias de comunicação emergiram, colado especificamente a necessidade do centro hegemônico na segunda metade do século em manter sua posição, não cativou adeptos. É claro que sempre vão existir os apocalípticos que bradam a determinação da rede pelos "fins militares" dos quais teria surgido. Mas uma análise ponderada, que tente sociologicamente compreender como se constituem as forças concretas em ação² encontra eco apenas nos debates da "economia política da comunicação" (Mosca 1996). Mesmo assim, fez-se menos do que se deveria no intuito de reconstruir o cenário real das práticas concretas e das arrumações institucionais que tornaram possível o aprimoramento destes meios, tarefa que só pode ser realizada pela investigação sobre o papel do poder político, sua relação com o universo econômico, e o lugar da ideologia nesse conjunto de relações.

Este artigo se afina com a segunda proposta. A tarefa é investigar parte do desenvolvimento pré-comercial da Internet, empreendimento que se estende de 1962 a 1995. Interessa parte deste período, contida entre 1979-1985, e que representa um momento menosprezado ou simplesmente esquecido. Em termos gerais, é possível dividir a constituição da Web em três momentos (Hart et al 1992). Cada um deles possui instituições e projetos que lhe são centrais. No primeiro, o personagem mais importante é a Darpa (Defense Advanced Research Projects Agency) e seu empreendimento, a Arpanet; no segundo, a NSF (National Science Foundation?), e a

\footnotetext{
${ }^{2}$ È certo que toda uma bibliografia específica investigou as relações sociais travadas na rede (Sá 2000, Wellman 1999). Todavia, seu objeto era a sociabilidade, e não as estruturas econômicas e políticas que tornaram viável que a Web se desenvolvesse como parte de um cenário maior, no qual entra em cena a exploração capitalista e a ação da burocracia de administração do poder. Muito mais Simmel, e muito menos Weber (ou Marx) estavam verdadeiramente em discussão.

3 A National Science Foundation encarna o projeto de que fomento deve constituir tarefa governamental contínua, apresentado no famoso relatório de Vannevar Bush, "Science - the endless frontier", publicado em 1945. Instituída em 05.1950 como uma forma de coordenar os investimentos em ciência e engenharia, atividades até este momento realizadas de forma independente por instituições específicas em setores particulares (como energia nuclear, biomedicina e defesa, privilegiadamente
} 
rede por ela criada, a NSFNET; no terceiro tal papel cabe ao Congresso dos EUA, e a NREN (National Research and Education Network).

Tal divisão choca-se com outro inventário, mais convencional, sobre o surgimento da rede. Das narrativas que repetidas vezes recontam sua criação, aquela incessantemente retomada versa sobre apenas um de vários projetos, a Arpanet, arbitrariamente eleita como único estágio pelo qual passaram todas as tentativas de criar uma estrutura digital de comunicação. Entre o experimento da Darpa e o uso comercial da Web, é como se nenhum outro agente tivesse desenvolvido coisa alguma ou houvesse capitaneado qualquer investida política digna de atenção. Tal argumento aparece em ícones da discussão. Em Levy (1990, 1997), por exemplo, as redes são estranhamente o desdobramento de um interesse militar em propor soluções a um possível "holocausto" pós Terceira Guerra. Daí, imediatamente a informática passa às mãos de empresários imbuídos do "espírito da contracultura" e se torna uma atividade profissional. Em nenhum momento se percebe que a Web é conseqüência de um investimento típico a trajetória dos EUA no pós-guerra, envolvendo o Estado e decisões político-econômicas que, no interior de sua estrutura, definem os rumos para inovação tecnológica a fim de que aquele centro mantenha seu papel dominante na competição industrial internacional.

A associação unidimensional entre tais redes e as forças militares aparece como um engano que obscurece o primeiro projeto organizado para interligação nacional de redes: entre Arpanet e o uso comercial da Internet, estão os experimentos da NSFNET e da NREN. É sobre o primeiro destes projetos que este texto se debruça. Seu problema diz respeito aos investimentos de Estado durante um momento de transição, no qual a comunidade acadêmica assume a hegemonia do desenvolvimento da Internet e em que a Darpa vai perdendo importância em comparação à NSF. O material usado são os amplos registros, em depoimentos e artigos deixados pelos envolvidos, assim como algumas sistematizações de fontes secundárias a partir daí produzidas. O enfoque aqui utilizado, todavia, tem como originalidade a abordagem deste desenvolvimento de um ponto de vista sociológico, recolocando as fontes em um enquadramento que preza por entender as ações do Estado a partir de sua análise

[Mazuzan 1994]), sua gênese tem relação direta com o intenso consenso sobre a necessidade de centralização destas atividades por um aparato de Estado. 
institucional, na tentativa de entender a arrumação burocrática indispensável a gênese de tais recursos.

\section{A "cibercultura" e seus problemas.}

Existe um mérito na discussão sobre "cultura das redes" que não deve ser desprezado. Pela primeira vez, optou-se por abordar sistematicamente não os aspectos técnicos da informática, mas sim os problemas sociais ai contidos. A solução adotada pelo grupo, porém, foi tratar de alguns poucos tópicos, aqueles possíveis de serem trabalhados pelas teorias disponíveis, e - muito mais relevante - pelos pressupostos ideológicos próprios aos escritores. Na verdade, a investigação sobre "novas tecnologias" quis transformar em realidade todas as expectativas nutridas pelos autores: em conjunto, elas se referem ao questionamento sobre as profundas transformações sociais contemporâneas. Certamente, mudanças intensas estão em curso. Mas não pelas razões imaginadas pelos “ciberculturalistas".

Vistos em conjunto, tais livros mostram-se como parte de um projeto, dos quais surgem como documentos de época marcados por orientações muito específicas. Lemos, a despeito da grande quantidade de fatos que discute, desdobra seu texto de um único argumento, infinitamente retomado. A informática, apropriada pela "cibercultura", teria se tornado um importante instrumento na luta contra a organização usual da modernidade. Racional em imensa medida, capaz de excluir seletivamente todos os elementos estranhos à constituição da sua gaiola de ferro, sua marca era desprezar o convívio descompromissado e o contato para além dos interesses da estrutura de vida ordenada e disciplinada. O declínio do indivíduo e a "tribalização" estaria, assim, diretamente conectado ao surgimento das caóticas redes digitais. Fantasias a parte, seu equívoco maior está em enxergar na "cibercultura” a realização de uma crítica social que se dá tão somente na sua imaginação. Lemos se orienta por um pressuposto ideológico muito forte. Cada parte do seu texto encontrase impregnada da suposição de que está em declínio a burocratização e a administração da vida cotidiana, e que, a partir daí, se encontra em voga outro tipo de arrumação da vida social. Sua expectativa máxima, deste modo, é encontrar o momento em que se institui o declínio da razão moderna e o (re)surgimento do "holismo". 
A crítica a racionalização e a massificação, herdada de Maffesoli é provocadora, e em sentido mais geral, amplamente necessária. Não é na opção de adotar uma postura específica que seu trabalho pede força. Instituir qualquer discussão mediante uma postura ideológica crítica particular não é um problema. Não se quer, aqui, defender qualquer positivismo vetusto, que proponha a análise "isenta”, supostamente "objetiva”, ou coisa que o valha. O erro de Lemos está em enquadrar uma realidade muito mais complexa e multifacetada em um quadro ideológico específico e limitado; mais grave: num contexto em que os pressupostos que defende tem pouca ou nenhuma relação direta com os fenômenos concretos. $\mathrm{O}$ problema está em forçar os dados para que eles adquiram, pelo efeito da força, o formato que a expectativa do autor sonha em tornar real. Lemos simplesmente ignora ou observa pela metade diversos dados, utilizando tão somente aquilo que se enquadra em seu modelo, enxergando alguma dimensão "libertária" num fenômeno surgido de um projeto altamente burocratizado.

Tema semelhante aparece na produção de Levy, com um escopo, porém mais amplo. Em um de seus livros (1990), a discussão sobre a "cultura das redes", alia-se à investigação de tais técnicas de comunicação em relação direta com a instituição da assim chamada "memória social". Entender os caminhos através dos quais se organiza a "inteligência" de uma sociedade é central para o autor. A cada momento histórico se relaciona um conjunto de técnicas através das quais se lida com o conhecimento; o que nada mais é além de um formato através pelo qual se institui certa racionalidade. A informática, então, liga-se diretamente a transformação deste formato racional de organização da inteligência. Em outro de seus textos (1997), o mesmo tema retorna. A transição da escrita para a informática, parte de um processo social mais amplo de esfacelamento da linearidade a qual a era moderna havia condenado o homem, ressurge. Porém, como novidade, o autor adiciona o conceito de "universal sem totalidade", uma forma de, mais uma vez, contrapor o "universal totalizante" da cultura letrada ao universo sem centro da "cibercultura". O problema se mantém, ainda que em novas roupas.

A observação da "memória”, e de suas transformações se torna, desta forma, a observação de um problema sociológico. Todavia, a análise que ai se pretende montar acontece, paradoxalmente, desprovida de teoria social. Instituições, 
estruturas, agentes e atores aparecem apenas de maneira lateral ${ }^{4}$, como elementos secundários ao lado da ordenação abstrata de inteligência que forma cada experiência de registro da "inteligência". O mesmo se dá com o fenômeno da "cibercultura". O computador pessoal surge como uma criação espontânea, conseqüência do engajamento voluntário em um projeto (1990, p. 44); as redes de comunicação brotam de um aumento "natural" de usuários, sem que nenhuma instituição tenha de intervir na sua gênese (1997, p. 32). O fantasma do mundo administrado, e o desejo inconteste de sua superação permanecem, ainda, como fantasmas a ser enfrentados, numa batalha sem fim, na qual em cada pequena hesitação do inimigo se vê o mais amplo sinal de incondicional vitória.

\section{A proposta de uma análise institucional do Estado.}

Nas discussões sobre economia política da comunicação existe uma tendência a analisar tão somente o desenvolvimento comercial da Web (Moraes 1998), como se este fosse o único de seus momentos. Tal interesse é de fato muito natural: afinal, nesta hora entram em cena desenvolvedores industriais de conteúdo que inauguram um tipo de exploração explicitamente mercantil da rede. Porém, a despeito do que se possa imaginar ao deparar-se com grupos econômicos de tamanho vulto operando com tais tecnologias, seu aprimoramento até tornar-se economicamente utilizável tem raízes quase que exclusivas em investimentos estatais. Toda a lógica de constituição de tal rede, seu formato técnico e a estrutura de administração por tal técnica demandada, são produto de um momento pregresso, indispensável para se compreender a direção seguida pela Internet comercial. Nesta fase estão contidas todas as decisões que, no período posterior, aparecerão sedimentadas e constituídas. Torna-se, assim, indispensável entender, do ponto de vista das análises de ações de Estado, o período não comercial da rede.

Entender as ações da burocracia que administra o poder estatal é projeto essencial, apresentado já por clássicos do quilate de Marx e Weber (Avineri 1968; Bendix 1966). A idéia de que a burocracia de Estado mantém relações intensas com os conflitos de classes e de grupos sociais lotados na sociedade civil, mas que age a partir de preceitos próprios e de interesses específicos, caros ao grupo que se

\footnotetext{
${ }^{4}$ Deficiências que, alias, foram indicadas por Sá (2001) em trabalho que remonta há anos atrás.
} 
encontra encarregado de administrá-lo, é base fundamental para se investigar a natureza do poder político. O enquadramento teórico utilizado neste artigo diz respeito a "análise institucional", proposta por Jessop (1982) a partir de uma leitura de Poulantzas (1971). Sua intenção é perceber quais os condicionantes históricos que tornam viável a configuração dos diferentes tipos de ação estatal. No período em questão, a base a qual essa burocracia se refere é o cumprimento de tarefa rotineira, designada por um projeto sobre ciência e tecnologia gerado no pós-guerra. Sua principal característica é ter claro que gastos com pesquisa e desenvolvimento devem ter relação direta com desenvolvimento industrial. $O$ imperativo de seu aproveitamento concreto por agentes econômicos que tem tecnologia como insumo propulsor de suas atividades é, assim, marca central.

O aprimoramento de tais redes irá resultar no elemento central para a assim chamada "economia baseada em conhecimento" (Freeman \& Perez 1988), constituída a partir do colapso do fordismo. Trata-se de um processo de destruição criadora do capitalismo (Schumpeter 1934), cujo traço essencial será a instauração de um outro paradigma tecno-econômico (Dosi 1984). É certo que a NSF está participando diretamente desse movimento de transformação do modo de produção. Todavia, seu padrão de conduta diz respeito, curiosamente, apenas às rotinas de trabalho para manutenção da hegemonia industrial dos EUA, dentro dos mesmos velhos moldes do paradigma industrial em que a estrutura sócio-econômica se movia. Aqui, a Fundação age segundo sua trajetória: utilizar recursos da ciência, especificamente da ciência da computação, de forma produtiva. Aqui, são coordenadas ações de Estado para que o desenvolvimento econômico, no qual o papel da academia fora historicamente preponderante, possa manter seu status, posição de destaque e primazia. E, aqui, do seio da relação Estado-mercado fordista parece nascer um dos elementos mais importantes para o regime de acumulação posterior.

\section{A (re)arrumação do Estado e o projeto de gestação das TIC}

$\square$ Os traços essenciais daquele percurso que a rede criada pela Darpa iria percorrer são amplamente conhecidos. O primeiro nó para comunicação em rede, instalado em 1969 na Universidade da Califórnia como resultado de investimentos do Departamento de Defesa e do esforço de desenvolvimento daquelas equipes lotadas 
no MIT, seria um projeto pioneiro que serviria de modelo para diversas outras iniciativas que se proliferam nos anos seguintes. Durante o período imediatamente anterior, haviam sido intensos os gastos em computação de grande porte: naquele momento, a questão passava a ser interligar estes diferentes centros e, assim, ampliar a sua produtividade (Denning 1989).

Diversas decisões, que apenas na aparência tem conteúdo tão somente técnico, tornam possível que a Arpanet se constitua como uma rede aberta, capaz de se interconectar com seus diversos clones. Tal recurso, que garante a flexibilidade indispensável a todo o conjunto, tem nome: trata-se do protocolo TCP/IP, vindo a público em meados de 1970. O caso é que, durante a década de 70, paralela à iniciativa da Darpa, a academia estadunidense tentaria participar desta vaga da comunicação digital financiando distintos projetos. Por um lado, é possível supor que se ao invés do protocolo TCP/IP tivesse sido adotada outra opção, menos maleável, a descentralização através da qual a Web se tornaria conhecida deixasse de existir. Mas, por outro lado -aqui mais importante - é viável imaginar que a preeminência da rede criada pela Darpa fosse muito menos intensa. Para um projeto independente de rede, era certamente muito mais simples e menos oneroso conectar-se a uma estrutura técnica aberta e disponível a ampliação.

Essa iniciativa de construir uma rede de comunicação funcional era, até aquele momento, uma ação na qual a Darpa exercera papel central: a academia se encontrava em posição extremamente secundária, ao menos até a proposta de uma rede financiada pela National Science Foundation se tornar real. A NSFNET é um divisor de águas em vários sentidos. Em termos técnicos, funciona como um imenso campo de provas para aquele formato essencial na constituição da Internet como estrutura viável. Em termos políticos, tal rede virá a ser o primeiro experimento em larga escala, capaz de interligar de costa a costa o território estadunidense, e assim se constituir como um imenso protótipo para o que viria a ser a Web comercial. E, para além de todas as razões expostas acima, importa o fato de que tal rede é o momento em que o desenvolvimento de tais ferramentas de comunicação deixa as mãos daquela burocracia de estado envolvida com o Departamento de Defesa e passa, definitivamente, para a universidade. 
A dificuldade das instituições acadêmicas em obter acesso era questão extremamente delicada. É verdade que, em 1979, a Darpa interligava diversas instituições: números apontam que 61 centros de pesquisa desfrutavam de tais recursos. Desse montante, porém, tão somente 15 estavam ligados a universidades; um valor que correspondia a somente $12 \%$ dos 120 departamentos de ciência da computação nos EUA (Hafner \& Lyon apud Keshan \& Shah 2001, p.102). As alternativas disponíveis para aqueles institutos que desejassem se conectar resumiam-se ao uso de linhas telefônicas, opção que resultava numa estrutura precária, limitada a circulação de arquivos pequenos através de uma alternativa cara (Comer 1983, p.748).

A lentidão da NSF em participar destes investimentos entra em choque com a dedicação já dispensada a centros de computação. Desde o final dos anos 50 uma quantidade grande de recursos vinha sendo investida: entre 1957 e 1972 e Fundação direcionara US\$ 85 milhões em equipamentos para universidades (Feldman \& Sutherland 1979, p.499); ao mesmo tempo, no intervalo de 1968 a 1973, haviam sido criados 30 centros de computação (Abbate apud Keshan \& Shah, p. 102), um interesse que persistiria até os anos 8o, com o projeto da "supercomputação" (OTA 1986). Todavia, a atenção aos recursos técnicos que permitem a conexão entre computadores permanecia atrofiada. A academia ficava para trás, em contradição com o próprio papel pelo qual havia se definido.

Como ponto de transição nesse processo histórico em que a hegemonia da Darpa cede lugar ao interesse da comunidade acadêmica em participar intensamente de tais empreendimentos, é possível indicar o ano de 1979 como um marco. Era então que acontecia certo encontro, sediado na Universidade de Wisconsin, e que reúne representantes de centros de pesquisa, instituições de fomento, e da própria Darpa. E era ali que, pela primeira vez, se dialogava sobre algum projeto relativo a interligação de todas as tentativas anteriores - menores - de se instituir redes de comunicação. A Arpanet, como projeto pioneiro, tinha sido modelo para diversas outras iniciativas semelhantes, ainda que dispersas, todas orientadas para o mesmo objetivo: o de ampliar as capacidades de comunicação. Investimentos pregressos como o da Theorynet, sediado na própria Wisconsin; da Samnet, em Toronto; e da Symbolnet, 
realizavam tarefas com base em estrutura de distribuição conhecidas como Telenet 5 . Algumas delas possuíam financiamento da NSF. Outras se conectavam a rede da Darpa (Denning, Hearn \& Kern 1983). Mas nenhuma contava com o esforço coeso e unidirecionado que a NSFNET viria a ter.

Existem, assim, duas demandas que parecem convergir. De um lado, a necessidade da academia em ampliar acesso à estrutura de comunicação digital; de outro, o interesse da Darpa em participar de um projeto interligado aos recursos da NSF. Conversas entre os representantes da Fundação a da Agência tratam especificamente desse ponto (Hart et al 1992, p.16); mas a incapacidade da Darpa em expandir e ampliar sua rede impede que tal desejo alcance resultado satisfatório (Denning, Hearn \& Kern 1983). Hart et al explicam tal contingência pelos "labirínticos processos de aquisição [de material] pelo Departamento de Defesa e demoras no envio de circuitos" (p.17), cujos resultados são atrasos sistemáticos nos cronogramas. A Fundação teria de caminhar com seus próprios pés; posição, porém, com resultados não dos mais desfavoráveis.

Nos anos que virão, criações indispensáveis a setores industriais com lugar central no desenvolvimento econômico começam a se tornar realidade. O risco de a academia ficar extremamente defasada como motor do aprimoramento técnico cresce na medida em que se acentua sua demora em participar de tal circuito. Discussões do momento põem esse perigo em destaque (Feldman \& Sutherland 1979). A NSFNET pode ser interpretada, assim, como uma tentativa de transferir o núcleo deste projeto. Ao invés de localizado no Departamento de Defesa, seu foco vai passar para a academia. A impossibilidade da Darpa em seguir adiante com o programa que havia iniciado, assim como a necessidade da Fundação de assumir uma postura mais ativa em tal cenário, torna possível que se altere a posição desvantajosa até então ocupada pela NSF. Na competição entre agências visando indicar qual delas seria responsável por garantir a posição dominante dos EUA em tecnologia de comunicação e informação, a Fundação se torna o personagem central deste programa de coordenação burocrática.

\footnotetext{
5 Telenet era uma rede comercial criada como um clone da Arpanet. Propriedade da Spring Corporation, empresa de telecomunicações de porte internacional, seria vendida posteriormente para a GTE Corporation (General Telephone and Electronics), empresa do mesmo setor, de porte menor, que, em 2000, iria ser fundida à Bell Atlantic para criação da Verizon Communications.
} 
A NSFNET surge, assim, exatamente no momento em que a preocupação do Estado se volta para a possibilidade de que hegemonia exercida desde os anos 70 pelos EUA na inovação de setores como eletrônica e computação seja ameaçada por nações como Japão, a então Alemanha Ocidental, França e Grã-Bretanha (NSF \& DoD 1982, p.7, 10, 12, 13). Em 1982, tal questão já se encontra suficientemente madura para levantar questionamentos recorrentes e sistemáticos sobre o tema, vindos agora do topo da pirâmide da administração estatal. O tópico, tratado em dois documentos importantes ("Lax Panel" [NSF \& DoD 1982] e "Bardon-Curtis report"; ver também OTA 1986) demanda, de forma organizada, um investimento coordenado entre institutos de pesquisa dedicados à ciência da computação e as agências envolvidas no projeto de redes.

É clara a decisão de que a rede a ser criada deveria interconectar tais centros de supercomputação, mantendo-se, porém, aberta ao maior número possível de campus de ensino (Kesan \& Shah 2001, p.104). A herança da Arpanet está ai claramente presente, não somente em termos ideológicos, com toda a sua retórica relativa a necessidade de potencializar as capacidades humanas de comunicação, mas certamente também em termos estratégicos. A Fundação segue os mesmos passos que a Darpa traçara, uma década antes, mantendo-se flexível o suficiente para atrair ao redor de si todo tipo de iniciativa que viesse a enriquecê-la. Dessa forma, o passo essencial seria garantir a adesão de todas as redes locais já existentes: para isso, adotar a herança técnica do TCP/IP seria essencial. Aparentemente ligado a problemas tão somente de engenharia, o IP mostra-se, assim, como questão sociológica central para se entender as contingências que cercam a arrumação burocrática e institucional do projeto.

\section{As heranças da Arpanet, e a NSFNET finalizada.}

Institucionalmente, a criação de uma rede administrada pela academia passa pela construção de um protótipo orientado pelas mesmas concepções técnicas. Sua importância não pode ser deixada de lado. Por um lado, todo o modelo de administração da NSFNET descende diretamente deste empreendimento. E, por outro, além de sua importância tecnológica, há ai uma extrema relevância política. Todo o consenso obtido junto à burocracia governamental sobre a importância de 
redes digitais, toda a respeitabilidade conquistada para o projeto, e todas as provas de que poderia se sustentar e ser auto-suficiente em longo prazo torna-se real através de outro empreendimento, batizado de CSNET (Computer Science Research Network). Sua criação é o primeiro resultado obtido a partir da reunião de Wisconsin, em 1979, e a primeira vez em que a NSF participa diretamente da administração deste tipo de rede.

Qualquer semelhança da futura Internet comercial com a estrutura da então hegemônica Arpanet tem a CSNET como elo. A montagem desta ligação, todavia, é intrigante. Curiosamente, o projeto inicial da rede acadêmica, elaborado entre 1979 e 1980, e que deveria explicitar o padrão pelo qual a futura rede viria a operar, simplesmente ignora os recursos da Darpa. Na realidade, nenhuma conexão entre as duas estruturas fora, naquele momento, prevista (Comer 1983; Denning, Hearn \& Kern 1983). A questão seria considerada somente após o projeto ser revisto pelos avaliadores da Fundação e retornar com a exigência de uso desta tecnologia. Neste momento se indica também que o financiamento para o programa será limitado: a NSF disponibilizaria US\$ 5 milhões e colocaria como condição que o projeto, após 1985, se sustentasse pelos seus próprios fundos. A conclusão é de que até estas condições serem apresentadas, o grupo não considerava como importante ou necessária a estrutura da Arpanet, simplesmente decidindo ignorá-la; ou, talvez, que a própria expectativa era de que fosse possível reconstruir por meios próprios todos os resultados já obtidos pela Darpa.

Através deste contato, de extrema proximidade e de imensa distância, migra o recurso da Agência que será, certamente, essencial para as redes de informática. Já se disse que é através do TCP/IP, tecnologia associada diretamente à Arpanet, que se torna possível ao projeto operar como uma "rede lógica"; ou seja, como um conjunto de outras redes operando interligadas. A partir da tecnologia do IP torna-se possível trocar tráfego, tarefa essencial quando se utiliza recursos de diversas outras procedências. Desta forma, a operação da CSNET seria nada além que a conexão entre a própria Arpanet, a já citada Telenet e a recém criada Phonenet (Quarterman \& Hoskins 1986). O mesmo modelo seria adotado pouco depois, na criação da espinha dorsal para a NSFNET, com o interesse de intercambiar recursos, agora com a CSNET, Arpanet e Bitnet. Uma solução conciliatória para recursos financeiros 
escassos parece, assim, ser um outro elemento essencial, grande parte das vezes ignorado, para que se garanta a estrutura "aberta" que definiria, em termos ideológicos, um traço marcante da nascente Internet.

Assim se encerra a primeira fase de tal projeto, ao mesmo tempo técnico, econômico e político. A partir de 1985, a NSF realizaria trabalhos de implementação de sua rede, tarefa que se estenderia até 1987, quando a estrutura finalmente se tornaria operacional. Seu formato definitivo seria o de uma imensa espinha dorsal que realizaria a troca de tráfego entre redes regionais menores, que por sua vez se ligariam às redes locais e às universidades (Keshan \& Shah 2001). Nenhuma transformação substantiva neste formato, apenas implementações para expansão de capacidade de tráfego teriam lugar nos próximos anos, quando se prepara a privatização desta estrutura e o licenciamento da rede comercial. O trabalho de constituição do que viria a ser a Internet está, finalmente, pronto.

\section{Conclusão}

Contrária à ilusão usual de que a Internet teria alguma relação com o temor militar do holocausto nuclear, uma análise mais atenta dos dados demonstra que os investimentos para criação de uma rede de comunicação em grande escala têm como base o interesse de manter a nação estadunidense como personagem mais importante na competição internacional por aprimoramento tecnológico. O resultado final, as redes comerciais, surge como resposta bem planejada a tais questões, no qual estão envolvidas complexas remodelações da administração burocrática de gastos governamentais em $\mathrm{P} \& \mathrm{D}$, momento em que o comando do desenvolvimento de tais redes informática sai das mãos da agência de Defesa e passa para a instituição de fomento central da comunidade acadêmica dos EUA.

No seio desta mudança está a primeira participação de capitalistas no investimento de construção de meios de comunicação. É a partir do projeto da Fundação que se abrirá espaço definitivo para a participação de corporações como IBM e MCI, indispensáveis na consolidação da estrutura do que viria ser a Internet comercial (NSF 1993; Kesan \& Shah 2001). É que a construção da espinha dorsal da NSFNET seria financeiramente possível somente a partir de licenças de computadores e de linhas de comunicação que, respectivamente, apenas o maior 
fabricante de máquinas e a maior operadora de teles poderiam oferecer. Desta forma, aquilo que iria custa US \$ 40 milhões, teve sua criação garantida pelo valor de US\$ 13 milhões (NSF 1993, p.7-8), total 32,5\% inferior. Aqui, se abre as portas para o capital, numa associação entre burocracia e empresários que cumpre aquilo que parece uma das tarefas básicas, neste período, do Estado moderno. Tal assunto, porém, é tema para outra discussão, própria a um momento posterior.

\section{Referências}

AVINERI, Shlomo. The social and political thought of Karl Marx. Cambridge: Cambridge University Press, 1968.

BENDIX, Reinhard. Max Weber: an intellectual portrait. Methuen, 1966.

CASTELLS, M. The rise of the network society. Oxford: Blackwell, 1996.

COMER, D. The computer science research network CSNET: a history and status report. Communications of the ACM archive, v. 26, n. 10, p. 747-53, 1983.

DENNING, P. "The ARPANET after Twenty Years," American Scientist, v. 77, p. 530-535, 1989.

DENNING, P.; HEARN, A. \& KERN, C. W. History and overview of CSNET. ACM SIGCOMM Computer Communication Review archive, v. 13, n. 12, 1983

DOSI, G. Technical change and industrial transformation. Great Britain: Macmillan Press, 1984.

FELDMAN, J. \& SUTHERLAND, W. Rejuvenating Experimental Computer Science: A Report to the National Science Foundation and Others. Communications of the ACM archive, v. 22. n. 9, p. 497-502, 1979.

FREEMAN \& PEREZ. "Structural crisis of adjustamente, business cycles and investiment behaviour". In Dosi et al. Technological change and economic theory. London: Pinter Publishers, 1988.

HART, J.; REED, R. \& BAR, F. The Building of the Internet: Implications for the Future of Broadband Networks. Berkeley Roundtable on the 
International Economy. Paper BRIEWP6o, 1992.

http://repositories.cdlib.org/brie/BRIEWP6o, 25 jun. 2004.

JESSOP, B. The capitalist state. Oxford: Martin Robertson, 1982

KESAN, J. P. \& SHAH, R. C. Fool us once shame on you - fool us twice shame on us: what we can learn from the privatizations of the internet backbone network and the domain name system. Washington University Law Quarterly, v. 79, 2001.

LEMOS, A. Cibercultura, tecnologia e vida social na cultura. Porto Alegre: Sulina, 2002.

LEVY, P. Cibercultura. Rio de Janeiro: Ed. 34, [1997]1999.

LEVY, P. Tecnologias da inteligência. Rio de Janeiro: Ed. 34, [1990]1993.

MAZUZAN, G. The National Science Foundation: A Brief History, 1994. http://www.nsf.gov/pubs/stis1994/nsf8816/nsf8816.txt, 13 jan. 2007.

MORAES, D. Planeta mídia. Campo Grande: Letra Livre, 1998

MOSCA, V. The political economy of communication. London: Sage, 1996.

NSF \& DOD. Report of the panel on large scale computing in science and engineering/Lax panel". Washington, DC: National Science Foundation \& Department of Defense, 1982.

http://www.pnl.gov/scales/docs/lax report 1982.doc, 20 jan. 2005.

NSF. Review of NSFNET. Washington, DC: Office of Inspector General, National Science Foundation, 1993.

http://www.nsf.gov/pubs/stis1993/oig9301/oig9301.txt, 25 jan. 2005.

OTA. Supercomputers: Government Plans \& Policies - A Background Paper, Washington, DC: Office of Technology Assessment, 1986.

http://govinfo.library.unt.edu/ota/Ota 3/DATA/1986/8628.pdf, 26 jan. 2005 .

POULANTZAS, N. Pouvoir politique et classes sociales. Paris: F. Maspero, 1971

QUARTERMAN, J. \& HOSKINS, J. Notable computer networks. Communication of the ACM , v. 29, n. 1, 1986

ROBERTS, L.G. "The Evolution of Packet Switching". Proceedings of the IEEE, v. 66, n. 11, p. 1307-1313, 1978.

SÁ, S. "Netnografias nas redes digitais". INTERCOM, Núcleo de Comunicação e Tecnologia. Anais... Campo Grande, 2001.

SÁ, S. "Utopias Comunais em rede". Lugar Comum, n. 12, p. 107-36, 2000.

SCHUMPETER, J. A. Teoria do desenvolvimento econômico. São Paulo: Abril Cultural, [1934]1982.

SIBILIA, P. Homem pós-orgânico. Rio de Janeiro: Relume Dumará, 2002

WELLMAN, B.\& GULIA, M. "Virtual Commuinities as Communities: Net Surfers Don't Ride Alone". In SMITH, M. \&. KOLLOCK, P. (ed.). Communities in Cyberspace. London: Routledge, 1999. 
